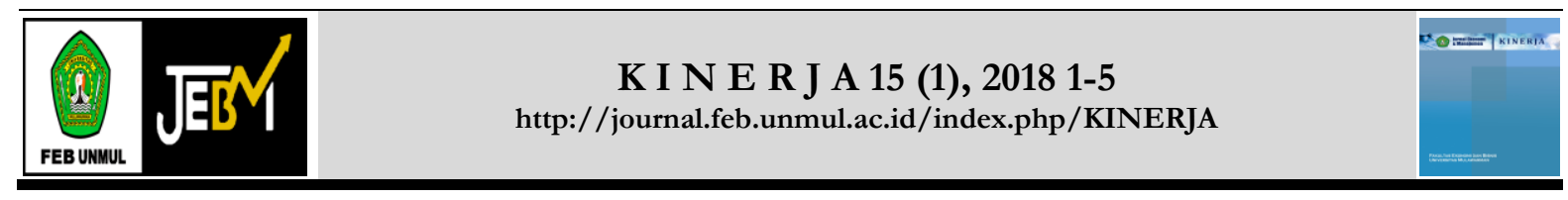

\title{
Pengaruh store atmosphere terhadap impulse buying pada bisnis ritel
}

\author{
Doddy Angga. A ${ }^{1}$, Syarifah HUdayah ${ }^{2}$, Mohammad Wasil ${ }^{3}$ \\ Fakultas Ekonomi dan Bisnis Universitas Mulawarman, Samarinda. \\ ${ }^{1}$ Email: doddyanggaa@gmail.com \\ ${ }^{2}$ Email: syarifah.hudayah@feb.unmul.ac.id \\ ${ }^{3}$ Email: mohammad.wasil@feb.unmul.ac.id
}

\begin{abstract}
Abstrak
Penelitian ini dilakukan untuk mengetahui pengaruh stimulus Store Atsmophere terhadap impulsive buying. Impulse Buying merupakan salah satu faktor yang di perhatikan para retailer atau produsen. Peningkatan pendapatan konsumen menyebabkan kebutuhan konsumen ikut meningkat, yang menyebabkan tingkat belanja konsumen juga ikut meningkat. Variabel bebas yang digunakan dalam penelitian ini adalah Exterior, General Interior, Store Layout, dan Interior Display, sedangkan variabel terikat dalam penelitian ini yaitu Pembelian Impulsif. Populasi pada penelitian ini yaitu Konsumen yang melakukan pembelian Impulsif di Swalayan 88 Kota Samarinda. Sampel pada penelitian ini sebanyak 80 orang responden. Teknik sampling yang digunakan pada penelitian ini adalah teknik sampling Purposif (purposive sampling). Faktor yang dapat mempengaruhi impulse buying terhadap sebuah pusat berbelanjaan adalah factor suasana toko atau lingkungan toko. Swalayan 88 merupakan salah satu toko yang menjual kebutuhan sehari-hari, swalayan 88 selalu menciptakan lingkungan belanja yang nyaman dan mengarah pada pendekatan pola perilaku positif, menciptakan impulse buying dalam setiap lini nya yang ada didalam swalayan 88 , dan selalu ada fitur-fitur yang menarik minat konsumen agar melakukan impulse buying. Hasil dari penelitian ini menunjukkan bahwa variabel Exterior, Genera Interior, Store Layout, dan Interior Display secara bersama-sama atau simultan memiliki pengaruh yang signifikan terhadap Pembelian Impulsif dengan nilai signifikansi $F$ sebesar $0,000(<\alpha 0,05)$. Nilai Adjusted R Square sebesar 0,880 atau 88.0\%. Sedangkan hasil dari penelitian ini menunjukkan secara parsial bahwa variabel Exterior, General Interior, Store Layout, dan Interior Display pengaruh yang signifikan terhadap Impulsif buying.
\end{abstract}

Kata Kunci: exterior; general interior; store layout; interior display; impulsif buying

\section{The effect of atmosphere store on impulse buying on retail business}

\begin{abstract}
This study was conducted to determine the effect of Store Atsmophere stimulus to impulsive buying. Impulse Buying is one of the factors in the attention of the retailers or producers. The increase in consumer income caused consumer needs to increase, causing the level of consumer spending also increased. The independent variables used in this study are Exterior, General Interior, Store Layout, and Interior Display, while the dependent variable in this research is Impulsive Purchase. The population in this study is Consumer who make impulsive purchase in Supermarkets 88 Samarinda City. The sample in this study were 80 respondents. Sampling technique used in this research is Purposive sampling technique (purposive sampling). Factors that can affect the impulse buying of a shopping center is a store atmosphere factor or store environment. Supermarkets 88 is one store that sells daily necessities, self-service 88 always creates a comfortable shopping environment and leads to a positive attitude pattern approach, creating impulse buying in every line that is inside self-service 88, and there are always interesting features consumer interest in impulse buying. The results of this study indicate that the Exterior, General Interior, Store Layout, and Interior Display variables simultaneously or simultaneously have a significant effect on Impulse Purchase with $F$ significance value of $0.000(<\alpha$ 0.05). Adjusted $R$ Square value of 0.880 or $88.0 \%$. While the results of this study show partially that the Exterior, General Interior, Store Layout, and Interior Display variables influence significantly on Impulsive buying.
\end{abstract}

Keywords: exterior; general interior; store layout; interior display; impulsive buying 


\section{PENDAHULUAN}

Store atmosphere (suasana toko) merupakan salah satu elemen penting dari bauran eceran yang mampu mempengaruhi proses keputusan pembelian konsumen. Saat melakukan pembelian, konsumen tidak hanya memperhatikan barang dan jasa yang ditawarkan oleh pengecer, tetapi juga lingkungan pembelian yang memberikan kenyamanan bagi konsumen, sehingga konsumen tersebut memilih toko yang disukai dan melakukan pembelian. Meskipun begitu, mengetahui dan memahami suasana toko bukanlah hal yang mudah karena suasana toko merupakan kombinasi dari hal- hal yang bersifat emosional. Berman \& Evan dalam Fuad (2010;2) membagi elemen-elemen store atmosphere kedalam empat elemen, yaitu: Store Exterior, General interior, Store layout, dan Interior display Setiap perusahaan selalu berusaha agar sukses dalam memenangkan persaingan dengan berusaha untuk dapat mencapai tujuan yaitu menciptakan dan mempertahankan pelanggan.

Impulse buying merupakan salah satu dari perilaku konsumen dalam menentukan suatu keputusan pembelian. Hetharie (2012) menyatakan perilaku impulse buying merupakan sebuah fenomena aktual dalam aktivitas pasar modern. Beberapa orang memiliki tingkat kecenderungan yang lebih tinggi untuk bereaksi terhadap impulse buying, sedangkan yang lain tidak menanggapi rangsangan tersebut Lin (2005). Wu and Tzung (2010) dalam penelitiannya menyatakan bahwa tekanan waktu dan tekanan ekonomi dapat dampak mempengaruhi pembelian tak terencana. Impulse buying dapat dipengaruhi oleh sejumlah faktor yang di antaranya salah satu faktor penting adalah faktor lingkungan, dan bagaimana konsumen menanggapi rangsangan yang diberikan oleh lingkungan konsumen tersebut baik lingkungan eksternal maupun lingkungan internal konsumen (Semuel, 2005).

Apabila elemen-elemaen yang mempengaruhi keputusan pembelian dapat dikelola dengan baik maka dapat mempengaruhi konsumen untuk membeli produk yang dihasilkan sehingga pengunjung meningkat dan tujuan pemasaran dapat tercapai. Swalayan 88 harus mampu mengimplementasikan strategi bersaing agar lebih dekat dengan konsumen untuk mengatasi ancaman dalam persaingan dan memperkuat posisi dalam persaingan.

\section{Kajiian Pustaka}

\section{Store Atmosphere}

Store Atmosphere merupakan salah satu elemen penting dari retailing mix yang mampu mempengaruhi proses keputusan pembelian konsumen, karena dalam proses keputusan pembeliannya konsumen tidak hanya memberi respon terhadap barang dan jasa yang ditawarkan oleh Retail.

\section{Elemen Store Atsmophere}

\section{Store Exterior}

Menurut Puspitasari (2012: 27) mengemukan penjelasan dari eksterior adalah elemen yang sangat penting dalam bisnis retail, sabagai media perantara yang menampilkan image perusahaan dan masyarakat Menurut Berman dan Evans dalam Fuad (2010:3) Store exterior adalah bagian depan toko mencerminkan kemantapan dan kekokohan spirit perusahaan dan sifat kegiatan yang ada di dalamnya, serta dapat menciptakan kepercayaan dan goodwill bagi konsumen Store exterior berfungsi sebagai identifikasi atau tanda pengenalan, sehingga sering menyatakan lambang.

Elemen-elemen eksterior ini terdiri dari sub elemen-elemen sebagai berikut:

Storefront

Storefront adalah sejumlah tampilan fisik dari exterior. Melalui storefront sebuah toko dapat menghadirkan sebuah citra toko yang unik, menarik yang akan mengundang konsumen untuk berbelanja. Storefront juga memiliki pengaruh yang baik bagi konsumen baru yang akan melewati toko yang belum dikunjungi sebelumnya. Ada sejumlah pilihan bagi pengecer (retailer) untuk mempertimbangkan dasar dari perencanaan storefront:

Modular structure.

Prefabricated (prefab) structure

Prototype store.

Recessed storefront

Unique Building design 


\section{Storefronts Marquee}

Marquee adalah suatu tanda yang digunakan untuk memajang nama atau logo suatu toko untuk tetap berdiri agar menarik perhatian. Marquee dapat dibuat dengan mencolok atau bercahaya dengan beberapa teknik pewarnaan, penulisan huruf atau penggunaan lampu neon yang memungkinkan kelebaran dari marquuee itu sendiri agar terlihat dengan jelas

\section{General interior}

General interior dari suatu toko harus dirancang untuk memaksimalkan visual merchandising. Seperti diketahui, iklan dapat menarik pembeli untuk datang ke toko, tapi yang paling utama yang dapat membuat penjualan setelah pembelian berada di toko adalah display. Display yang baik adalah yang dapat menarik perhatian para konsumen dan membantu mereka agar mudah mengamati, memeriksa dan memilih barang-barang, dan akhirnya melakukan pembelian ketika konsumen masuk ke dalam toko.

\section{Store layout}

Menurut Devi Puspitasari (2012: 30) Layout toko adalah gambar tampak atas yang berskala dari sebuah area toko yang memperlihatkan pembagian area. Tujuan layout toko adalah untuk menciptakan lalu lintas yang hidup di dalamnya dengan mengekspos barang dagangan sebanyak mungkin kepada konsumen agar penjualan optimal Store layout atau tata letak toko, merupakan rencana untuk menentukan lokasi tertentu dan pengaturan dari jalan/gang di dalam toko yang cukup lebar yang memudahkan para konsumen untuk berlalulalang di dalamnya. Store layout akan mengundang masuk atau menyebabkan konsumen menjauhi toko tersebut ketika konsumen tersebut melihat bagian dalam toko melalui jendela etalase atau pintu masuk. Layout yang baik akan mampu mengundang konsumen untuk betah berkeliling lebih lama dan membelanjakan uangnya lebih banyak.

\section{Interior display}

Interior display merupakan tanda-tanda yang digunakan untuk memberikan informasi kepada konsumen untuk mempengaruhi suasana lingkungan toko, dengan tujuan utama untuk meningkatkan penjualan dan laba toko tersebut. Interior display terdiri dari:

\section{Theme setting}

Theme setting menunjukan penawaran prroduk dalam lingkungan dan atmosfer yang tersedia yang berada dalam toko

\section{Racks and cases}

Rak dan penyimpanan digunakan unutuk menggantung atau memajang produk dengan rapi.

Cut cases and dump bins Kegunaan dari cut cases dan dump bins adalah untuk mengurangi biaya dalam melakukan pemajangan produk yang terbuat dari karton.

\section{Posters, signs, and cards}

Poster dan kartu penanda digunakan untuk memberikan informasi tentang produk dan lokasi produk agar memudahan konsumen dalam mencari produk yang diinginkan.

\section{Impulsif Buying}

Pembelian Impulsif didefinisikan sebagai pembelian yang dibuat di dalam toko yang berbeda dari perencanaan konsumen untuk membuat prioritas saat memasuki toko (Hawkins et al 2000:610). Menurut Rook (1987) pembelian impulsif terjadi ketika pengalaman konsumen tiba- tiba, terlalu sering, dan keinginan terus menerus untuk membeli sesuatu dengan segera.pembelian impulsif juga terjadi dengan tergesa-gesa yang sehubungan dengan berkurangnya pada sebuah konsekuensi dalam pembelian. pembelian impulsif juga terjadi dengan tergesa -gesa yang sehubungan dengan berkurangnya pada sebuah konsekuensi dalam pembelian. Pembelian secara impulsif cenderung mengganggu pemikiran sikap konsumen, ketika pembelian secara pemikiran lebih dari sekedar bagian dari rutinitas sehari-hari. Pembelian impulsif lebih emosional daripada rasional, dan lebih seperti sikap "buruk" daripada "baik". Dan pada akhirnya konsumen lebih seperti kehilangan kendali ketika membeli secara impulsif daripada ketika membuat pembelian secara pemikiran. Sedangkan menurut Beatty and Ferrel (1998) pembelian impulsif adalah terjadi tiba - tiba dan pembelian dengan segera tanpa niat sebelum belanja untuk membeli produk secara spesifik atau untuk memenuhi tugas pembelian secara spesifik. 


\section{Hipotesis}

H1: Store Exterior berpengaruh secara signifikan terhadap Impulsif Buying.

H2: General Interior berpengaruh secara signifikan terhadap Impulsif Buying

H3: Store Layout berpengaruh secara signifikan terhadap Impulsif Buying

H4: Interior Display berpengaruh secara signifikan terhadap Impulsif Buying.

\section{METODE}

Didalam penelitian ini peneliti mengambil objek di Swalayan 88. Dari keseluruhan populasi yang didapatkan dilapangan terdapat 80 responden Jenis data yang digunakan adalah metode deskriptif Kualitatif yaitu suatu metode dalam meneliti sekelompok manusia, suatu objek, suatu system pemikiran atau suatu peristiwa di masa sekarang. Dimana tujuannya untuk membuat deskriptif, gambaran atau lukisan secara sistematis, faktual dan akurat mengenai fakta-fakta secara hubungan antara variabel.

Untuk memperoleh data serta keterangan yang diperoleh dalam penyusunan skripsi ini, penulis menggunakan beberapa metode pengumpulan data yang relevan untuk memecahkan dan menganalisis masalah yang telah dikemukakan sebelumnya. Cara yang dilakukan sebagai berikut:

Penelitian Lapangan (Field Research) yaitu ada penelitian yang dilakukan dengan cara pengamatan langsung dilapangan untuk memperoleh data dan informasi. Penelitian ini dilakukan dengan cara:

Wawancara yaitu suatu bentuk penelitian yang dilakukan dengan mewawancarai pihak-pihak yang bersangkutan di lapangan untuk memperoleh data yang berhubungan dengan pembahasan.

Kuesioner yaitu suatu bentuk penelitian yang dilakukan dengan membagikan daftar pertanyaan kepada konsumen Toko Fera Accessories.

Metode analisis data adalah suatu metode yang digunakan untuk mengolah hasil penelitian untuk memperoleh suatu kesimpulan. Adapun metode analisis data yang digunakan dalam penelitian ini adalah analisis linier regresi berganda. Analisis linier regresi berganda digunakan untuk mengetahui hubungan antara variabel bebas dan variabel terikat yaitu antara Store exterior (X1), General interior (X2), Store layout (X3), Interior display (X4) terhadap keputusan pembelian (Y). Selain itu, analisis linear berganda juga digunakan untuk mengetahui sejauh mana pengaruh antara variabel bebas da variabel terkat. Adapun rumus analisis lenier berganda yang digunakan dalam Sugiyono (2007) adalah sebagai berikut:

$$
\mathrm{Y}=\mathrm{a}+\mathrm{b} 1 \mathrm{X} 1+\mathrm{b} 2 \mathrm{X} 2+\mathrm{b} 3 \mathrm{X} 3+\mathrm{b} 4 \mathrm{X} 4+\mathrm{e}
$$

Dimana:

\begin{tabular}{|c|c|}
\hline Y & $=$ Variabel terikat (keputusan pembelian) \\
\hline $\mathrm{X} 1$ & $=$ Variabel exterior \\
\hline $\mathrm{X} 2$ & $=$ Variabel general interior \\
\hline $\mathrm{X} 3$ & $=$ Variabel store layout \\
\hline $\mathrm{X} 4$ & $=$ variabel interior display \\
\hline A & $=$ Bilangan konstanta \\
\hline b1, b2, b3, b4 & $=$ Koefisien regresi \\
\hline & $=$ Residual atau predictor error \\
\hline
\end{tabular}

\section{HASIL DAN PEMBAHASAN}

Berdasarkan hasil penelitian yang telah dilakukan, diketahui bahwa store Exterior berpengaruh positif terhadap Impulse Buying.

Oleh karena itu, dapat dikatakan bahwa semakin baik pengelolaan terhadap store exterior maka semakin baik pula persepsi konsumen atas store exterior tersebut dan semakin besar pula dorongan konsumen untuk melakukan pembelian pada toko tersebut.

Hasil penelitian ini mendukung dan memperkuat hasil penelitian yang dilakukan sebelumnya Berdasarkan hasil penelitian yang telah dilakukan, diketahui bahwa General Interior berpengaruh positif terhadap pembelian Impulse Buying. Oleh karena itu, dapat dikatakan bahwa semakin baik pengelolaan terhadap General Interior maka semakin baik pula persepsi konsumen atas General Interior tersebut dan semakin besar pula dorongan konsumen untuk melakukan pembelian pada toko tersebut.

Berdasarkan hasil penelitian yang telah dilakukan, diketahui bahwa Store Layout berpengaruh positif terhadap keputusan pembelian Impulse Buying. Store Layout berpengaruh positif terhadap 
keputusan pembelian Impulse Buying. Oleh karena itu, dapat dikatakan bahwa semakin baik pengelolaan terhadap Store Layout maka semakin baik pula persepsi konsumen atas General Interior tersebut dan semakin besar pula dorongan konsumen untuk melakukan pembelian pada toko tersebut.

Berdasarkan hasil penelitian yang telah dilakukan, diketahui bahwa Interior Display berpengaruh positif terhadap keputusan pembelian Impulse Buying. Oleh karena itu, dapat dikatakan bahwa semakin baik pengelolaan terhadap Interior display maka semakin baik pula persepsi konsumen atas interior display tersebut dan semakin besar pula dorongan konsumen untuk melakukan pembelian pada toko tersebut.

\section{SIMPULAN}

Berdasarkan hasil penelitian dan pembahasan pada bab IV, maka dapat diambil beberapa kesimpulan sebagai berikut.

Didapatkan hasil pengujian secara persial atau individu diketahui bahwa semua variabel didalam penelitian ini seperti Store Exterior, General Interior, Store Layout dan Interior Display mempunyai pengaruh yang positive dan signifikan.

Setelah dilakukan pengujian secara simultan didapatkan hasil bahwa variabel independen mampu mempengaruhi variabel dependen secara bersama- sama atau simultan.

\section{DAFATR PUSTAKA}

Arikunto, Suharsimi. (1998). Prosedur Penelitian. Jakarta: Rineka Cipta

Berman, Barry and Joel R. Evans. (2007). Retail Management. 10th edition. New Jersey. Pretice: Hall Inc.

Engels, James F, et al. (1995). Perilaku Konsumen Edisi 6, Jilid 1. (Alih bahasa: Drs.

Harmancioglu, N., Finney, R. Z., and Joseph, M. 2009. Impulse purchases of new product: an empirical analysis, Journal of Product and Brand Management, Vol. 18, No. 1, pp. 27-37

Hetharie, J.A. (2012). "Peran Emosi Positif sebagai Mediator Stimulus Lingkungan Toko dan Faktor Sosial terhadap Impulse Buying Tendency pada Matahari Departement Store Kota Ambon," Jurnal Aplikasi Manajemen, Vol. 10 No. 4, pp. 890 - 898.

Kotler, Philip. (2003). Manajemen Pemasaran Edisi 6, Jilid 2.

Kotler, Philip dan Amstrong, Gary. (2008) Principles of Marketing. $11^{\text {th }}$ Edition.New Jersey: Prentice Hall. Pearson Education, Inc, Upper Saddle River, New Jersey.

Kotler, Philip \& Keller, Kevin Lane. (2012). Manajemen Pemasaran Edisi 13. (Alih bahasa: Bob Sabran MM). Jakarta: Penerbit Erlangga.

Michael and Barton Weitz. 2007. Retailing Management. Edisi ketujuh. International Edition. New York: McGraw-Hill.

Malhotra, N. K. 2009. Riset Pemasaran. Edisi keempat. Jakarta: PT Indeks.

Ma’ruf, Hendri. 2006. Pemasaran Ritel. Jakarta: Gramedia Pustaka Utama.

Nurmawati, Endang. (2012). "Pengaruh Sore Atmosphere terhadap Keputusan Pembelian Konsumen Mulia Toserba dan Swalayan Godea Sleman. Yogyakarta". Skripsi. Universitas Negeri Yogyakarta

Umar, Husain. 2008. Riset pemasaran dan perilaku konsumen. Jakarta: gramedia rustaka utama

Utami, Christina Whidya. 2010.

Manajemen Ritel: Strategi dan Implementasi Modern. Edisi Pertama. Jakarta: Salemba Empat. 